Original Article

\title{
Cytotoxic effect of Aggregatibacter actinomycetemcomitans Lipopolysaccharide on Human Leukemia Cell Lines and Human Gingival Fibroblasts
}

\author{
Masanori Saito ${ }^{1}$, Osamu Tsuzukibashi ${ }^{2}$, Noriko Shinozaki-Kuwahara ${ }^{1}$, and Kazuko Takada ${ }^{1}$ \\ Departments of ${ }^{1}$ Oral Microbiology and ${ }^{2}$ Laboratory Medicine for Dentistry, Nihon University School of Dentistry at \\ Matsudo, Matsudo, Chiba 271-8587, Japan
}

\section{Article History}

Received 28 August 2012

Accepted 12 September 2012

Keywords :

Aggregatibacter actinomycetemcomitans, lipopolysaccharide, cytotoxic effect

\begin{abstract}
Aggregatibacter actinomycetemcomitans is implicated in the etiology of aggressive periodontitis and chronic periodontitis. Lipopolysaccharide (LPS) is a major constituent of the outer membrane of Gram-negative bacteria. LPS from Aggregatibacter actinomycetemcomitans (Aa-LPS) and Escherichia coli (Ec-LPS) was isolated by the hot phenol-water method and partially purified on a column. The purpose of this study was to compare the properties of Aa-LPS with Ec-LPS. Aa- and Ec-LPS showed different patterns in the results of SDS-PAGE. Furthermore, the total sugar and limulus activity of Aa-LPS were different from those of Ec-LPS. The cytotoxic effect of Aa-LPS was in a time- and dose-dependent manner. Aa-LPS had a strong cytotoxic effect on human leukemia cell lines and human gingival fibroblasts compared with Ec-LPS. These results suggested that the difference in structure, total sugar amount and limulus activity of Aa-LPS from those of Ec-LPS or the cell difference may participate in the cytotoxic effect.
\end{abstract}

\section{Introduction}

Aggregatibacter actinomycetemcomitans, a Gram-negative bacillus and a member of the oral microflora, is thought to play a major role in the development of aggressive periodontal disease, involving rapid gingival and alveolar bone destruction $(1,2)$. This bacterium produces several virulence factors, including the production of lipopolysaccharide (LPS), cytolethal distending toxin, a chaperonin and a leukotoxin $(3,4,5,6,7,8,9)$. It is likely that leukotoxin plays an important role in A. actinomycetemcomitans pathogenesis by helping the bacterium evade host immune responses $(5,6)$. The lipopolysaccharide molecules of Gramnegative bacterial cell walls are the antigen ( $\mathrm{O}$ antigen) as well as the source of endotoxic activity of these bacteria (10). LPS from A. actinomycetemcomitans (Aa-LPS) is a potent inducer of pro-inflammatory mediator, related with adverse pregnancy outcomes $(11,12)$, osteoclast activation (13), complement activation (14) and direct B cell activation (15). In this study, we investigated the cytotoxic effect of

Correspondence to :

Masanori Saito

E-mail : saito.masanori@nihon-u.ac.jp
Aa-LPS on human promyelocytic leukemia cells (HL60 cells), the human acute monocytic leukemia cell line (THP1 cells) and human gingival fibroblasts (HGFs) compared with LPS from Escherichia coli (Ec-LPS).

\section{Materials and Methods}

\section{Cell culture}

HL60 cells, THP-1 cells (Cell Bank, Riken Bioresource Center, Ibaraki, Japan) and HGFs (obtained from the Department of Renascent Dentistry, Nihon University School of Dentistry at Matsudo, Chiba, Japan) were maintained in RPMI 1640 medium (Wako, Osaka, Japan) supplemented with $10 \%$ fetal bovine serum (FBS; Invitrogen, Carlsbad, CA) for $48 \mathrm{~h}$ at $37^{\circ} \mathrm{C}$ under a $5 \% \mathrm{CO}_{2}$ atmosphere. Before use, the medium was discarded and the adherent HGFs were harvested with Trypsin-EDTA (0.25 w/v\% trypsin, 1 mmol L ${ }^{-1}$ EDTA-4Na, Wako, Osaka, Japan) for $5 \mathrm{~min}$ at $37^{\circ} \mathrm{C}$. HL60 cells, THP-1 cells and float HGFs were washed twice in phosphate-buffered saline (PBS; Wako, Japan) to remove the medium and then resuspended in $\mathrm{PBS}$. 


\section{Bacterial cultures and LPS preparation}

A. actinomycetemcomitans strain Y4 and E. coli strain K12 were grown in brain-heart infusion broth supplemented with 1\% yeast extract (Becton, Dickinson and Co., Sparks, $\mathrm{MD})$ at $37^{\circ} \mathrm{C}$ in a $5 \% \mathrm{CO}_{2}$ atmosphere. LPS was extracted using the hot phenol-water method and subsequently treated with DNase 1, RNase $\mathrm{A}$ and proteinase $\mathrm{K}$ as described by Moran et al. (16). Furthermore, crude LPS was partially purified by Sephacryl S-200 HR (Amersham Pharmacia Biotech AB, Uppsala, Sweden) as described by Takada et al. (17). The protein concentration in LPS was measured in a standard protein assay (DC protein assay; Bio-Rad, Richmond, CA). The total sugar in LPS was determined by the phenol-sulfuric acid method (18). LPS was quantitated by the Toxin Sensor Chromogenic Limulus amoebocyte Lysate (LAL) endotoxin assay kit (GenScript, NJ, USA), according to the manufacturer's instructions. In brief, standards, samples and LAL reagent were dispensed into endotoxin-free vials; $1 \mathrm{mg} \mathrm{m}^{-1} \mathrm{Aa}$ - and Ec-LPS were diluted prior to analysis. Activity (endotoxin units $\mathrm{ml}^{-1}$; EU $\mathrm{ml}^{-1}$ ) were determined by comparison to an Escherichia coli standard solution. Partially purified LPS (10 $\mathrm{kg}$ dry weight) was analyzed by $12.5 \%$ sodium dodecyl sulfatepolyacrylamide gel electrophoresis (SDS-PAGE). As a molecular weight marker, a dual-color, prestained Precision Plus protein standard (Bio-Rad Laboratories, Richmond, CA) was used. After electrophoresis, the gel was stained using a Silver Stain Kit (Wako, Osaka, Japan).

\section{Measurement of cytotoxic effect of Aa-LPS at various doses}

Measurement of the dose-dependent cytotoxic effect of Aa-LPS for each cell type was performed by broth dilution and calculation of the percent cell lysis. One milliliter of the reaction mixture, including $2 \times 10^{6}$ cells of each cell type and 0 to $500 \mu \mathrm{g}$ dry weight of Aa-LPS in PBS, was incubated at 37 ${ }^{\circ} \mathrm{C}$ for $30 \mathrm{~min}$ in an atmosphere of $5 \% \mathrm{CO}_{2}$ in air. After incubation, the reaction mixtures were placed on ice, $100 \mu \mathrm{l}$ trypan blue (0.4\%) was added, and surviving cells were counted in a hemocytometer. At least four fields were counted and cell numbers were averaged for each assay. Percent lysis was calculated by dividing the number of surviving cells by the number of cells in the negative control. The cytotoxic effect of Ec-LPS was examined as a comparison of Aa-LPS.

Measurement of cytotoxic effect of Aa-LPS at various times
The time-dependent cytotoxic effect of Aa-LPS for each cell was measured by calculating the percent of cell lysis. One milliliter of the reaction mixture, including $2 \times 10^{6}$ cells of each cell type and $500 \mathrm{\mu g}$ dry weight of Aa-LPS, was incubated at $37^{\circ} \mathrm{C}$ for 0 to $45 \mathrm{~min}$ in an atmosphere of $5 \% \mathrm{CO}_{2}$ in air. Calculations were performed as described above.

\section{Statistical analysis}

The data are presented as the mean \pm the standard deviation and compared using the two-tailed Student's t test. A P value of $<0.05$ was considered significant.

\section{Results}

Characterization of $A a$ - and Ec-LPS

The amount of Aa-LPS obtained from $1 \mathrm{~L}$ culture was almost one-third of $E$. coli (Table 1). The concentration of sugar in Aa- and Ec-LPS was 70.2 and $91.7 \mathrm{mg} \mathrm{mg}^{-1}$, respectively; this difference was statistically significant $(P$ $<0.05)$. The concentration of protein in Aa- and Ec-LPS was 43.9 and $39.8 \mu \mathrm{g} \mathrm{mg}^{-1}$, respectively; The difference was not statistically significant $(P>0.05)$. Activities of Aa- and Ec-LPS were $9.7 \times 10^{6}$ and $7.3 \times 10^{6} \mathrm{EU} \mathrm{mg}^{-1}$, respectively; this difference was statistically significant $(P<0.05)$. SDSPAGE pattern of Aa-LPS showed strong silver staining only in the lower-molecular-weight region of the gel (Fig. 1A). On the other hand, the SDS-PAGE pattern of Ec-LPS by silver staining revealed progressive ladder-like bands up the gel (Fig. 1B).

Dose-dependent cytotoxicity of Aa-LPS against HL60 cells, THP-1 cells and HGFS

The dose-dependent cytotoxicity of Aa-LPS on each cell was examined. Aa- and Ec-LPS-untreated HL60 cells as a control showed $4.9 \%$ of cell lysis after $30 \mathrm{~min}$ incubation. HL60 cells treated with 500, 250, and $125 \mu \mathrm{g} \mathrm{ml}{ }^{-1}$ Aa-LPS accounted for $69.0 \%, 28.7 \%$ and $18.3 \%$ of cell lysis, respectively (Fig.2A). HL60 cells treated with 500, 250, and $125 \mathrm{mg} \mathrm{ml}^{-1}$ Ec-LPS accounted for $32.3 \%, 21.3 \%$ and $13.3 \%$ of cell lysis, respectively.

LPS-untreated THP-1 cells as a control showed $6.2 \%$ of cell lysis after $30 \mathrm{~min}$ incubation. THP-1 cells treated with 500, 250, and $125 \mu \mathrm{g} \mathrm{ml}^{-1}$ Aa-LPS accounted for $92.2 \%$, $70.2 \%$ and $55.3 \%$ of cell lysis, respectively (Fig. 2B). THP-1 cells treated with 500, 250, and $125 \mu \mathrm{g} \mathrm{ml}^{-1}$ Ec-LPS accounted for $37.1 \%, 21.0 \%$ and $15.2 \%$ of cell lysis, respectively. 
Table 1 Purification of Aa- and Ec-LPS from 1L culture

\begin{tabular}{ccccc}
\hline & $\begin{array}{c}\text { dry weight } \\
(\mathrm{mg})\end{array}$ & $\begin{array}{c}\text { sugar } \\
(\mathrm{mg})\end{array}$ & $\begin{array}{c}\text { protein } \\
(\mathrm{mg})\end{array}$ & $\begin{array}{c}\text { limulus activity } \\
(\mathrm{EU})\end{array}$ \\
\hline Aa-LPS & 11.4 & 0.8 & 0.5 & $1.1 \times 10^{8}$ \\
Ec-LPS & 32.7 & 3.0 & 1.3 & $2.4 \times 10^{8}$ \\
\hline
\end{tabular}

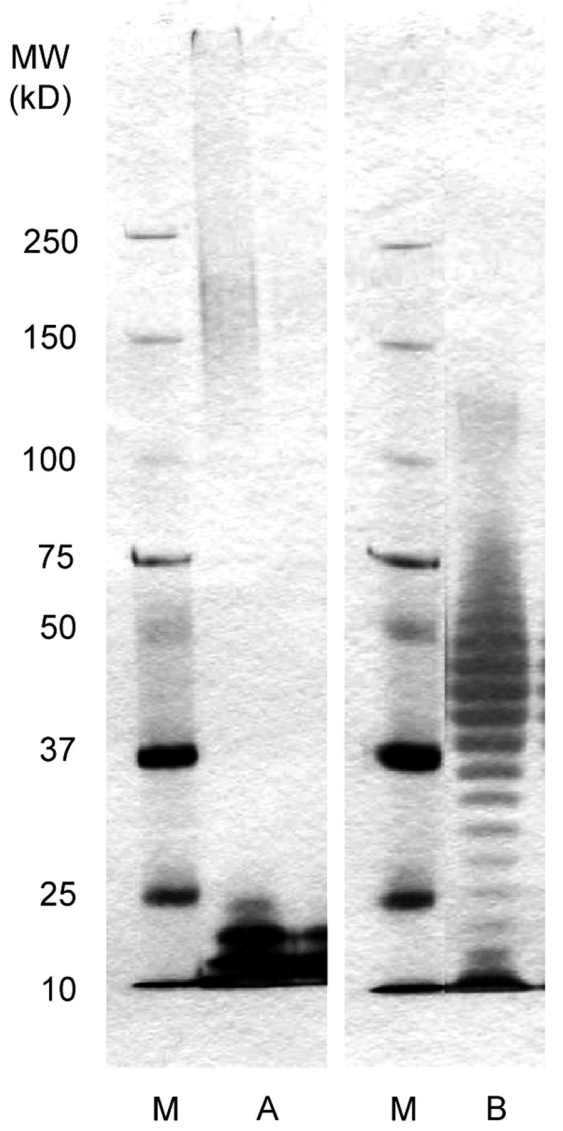

Fig. 1 Silver-stained SDS-PAGE pattern of Aa-(A) and Ec-LPS (B). A $10 \mu \mathrm{g}$ amount of partially purified LPS was applied and stained by the silver staining method. M: molecular weight marker.

LPS-untreated HGFs as a control showed $7.8 \%$ of cell lysis after $30 \mathrm{~min}$ incubation. HGFs treated with 500,250 , and $125 \mu \mathrm{g} \mathrm{ml}^{-1}$ Aa-LPS accounted for $93.4 \%, 58.8 \%$ and $29.8 \%$ of cell lysis, respectively (Fig. 2C). HGFs treated with 500, 250, and $125 \mu \mathrm{g} \mathrm{ml}^{-1}$ Ec-LPS accounted for $27.3 \%$, $24.3 \%$ and $14.7 \%$ of cell lysis, respectively. The cytotoxic effect of Aa-LPS on HL60 cells, THP-1 cells and HGFs was in a dose-dependent manner and stronger than Ec-LPS.

Time-dependent cytotoxicity of Aa-LPS against HL60 cells, THP-1 cells and HGFs

Fig. 3 shows the time-dependent cytotoxic effect of Aa-
LPS on HL60 cells, THP-1 cells and HGFs. Each surviving cell was decreased immediately and rapidly with Aa-LPS. Moreover, the cytotoxic effect of Aa-LPS on HL60 cells after 45 min incubation was almost 20\% lower than on other cells. Each surviving cell treated with Ec-LPS decreased gradually and slowly with increasing incubation time. Moreover, the cytotoxic effects of Ec-LPS on HGFs at 45 min incubation were almost 15\% lower than on other cells.

\section{Discussion}

It was reported that leukotoxin may play a role in host cell killing and immune evasion in vivo $(5,6)$. A. actinomycetemcomitans strain JP2 is well known to have high leukotoxicity (19); however, all A. actinomycetemcomitans which we isolated from patients with chronic and aggressive periodontitis had low leukotoxicity (data not shown); therefore, we thought that cell components of $A$. actinomycetemcomitans other than leukotoxin participated in periodontitis. We particularly focused on LPS of A. actinomycetemcomitans.

The cytotoxic effect of Aa-LPS and Ec-LPS occurred in a dose- and time-dependent manner. A high concentration of Aa-LPS showed strong and rapid cytotoxicity on each cell. The cytotoxic effect of Aa-LPS was stronger than Ec-LPS. Similar results were obtained in each cell type; however, when comparing the effect of Aa-LPS in each cell type, cell lysis of HL60 cells by Aa-LPS was lower than THP-1 cells and HGFs. It was thought that the cytotoxic effect of AaLPS depended on cell differences. In addition, it was thought that the cytotoxic difference between HL60 cells and HGFs depended on the difference between the cell line and primary cells. Furthermore, the cytotoxic effect of Ec-LPS was slightly different between the human leukemia cell line and HGFs $(P>0.05)$

It is difficult to consider that the high concentration of $\mathrm{Aa}$ LPS used in these experiments could accumulate in the oral cavity; however, it was suggested that Aa-LPS participates in periodontal disease by having shown a cytotoxic effect that was stronger than Ec-LPS

Aa-LPS mainly consisted of lower-molecular-weight components. Moreover, the total sugar and limulus activity of Aa- and Ec-LPS were different. It was thought that structural differences between Aa-LPS and Ec-LPS or cell differences participated in cytotoxicity.

\section{Acknowledgments}

We express our thanks to Dr. M. Hirasawa for critical 
A

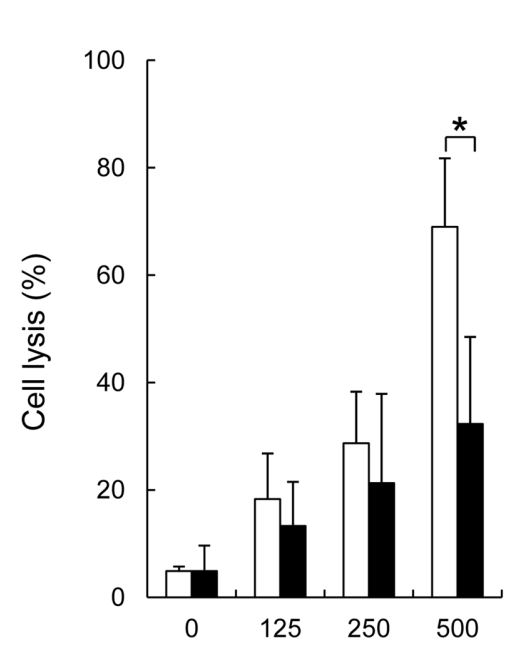

B

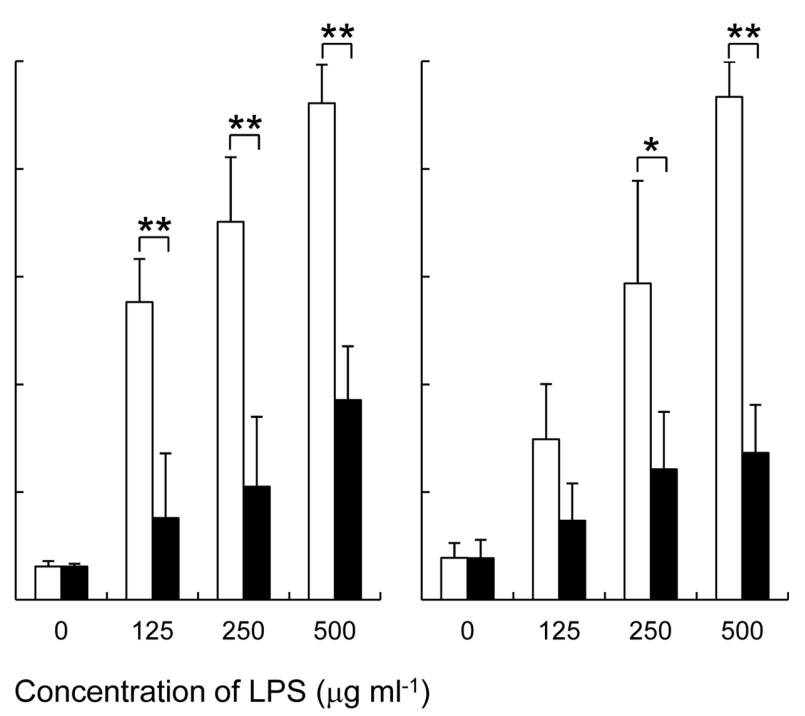

Fig. 2 Dose-dependent effect of LPS on HL60 cells (A), THP-1 (B) cells and HGFs (C). Thirty min incubation with various concentrations of Aa- (white bar) and Ec-LPS (black bar). The results are expressed as the mean \pm standard deviation of four independent experiments. Single asterisk indicates $P<0.05$; double asterisk indicates $P<0.01$.

A

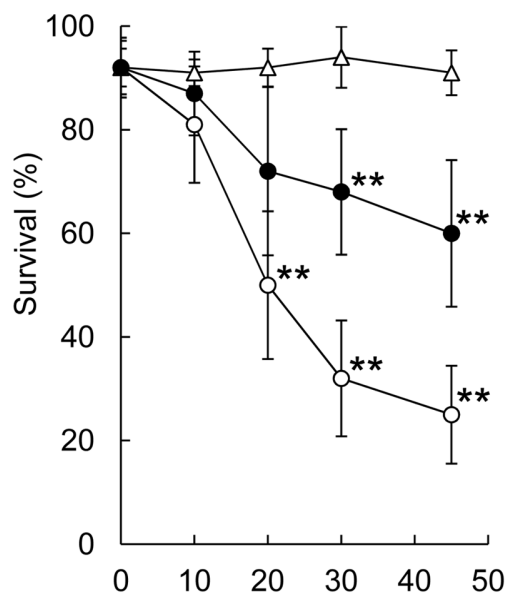

B

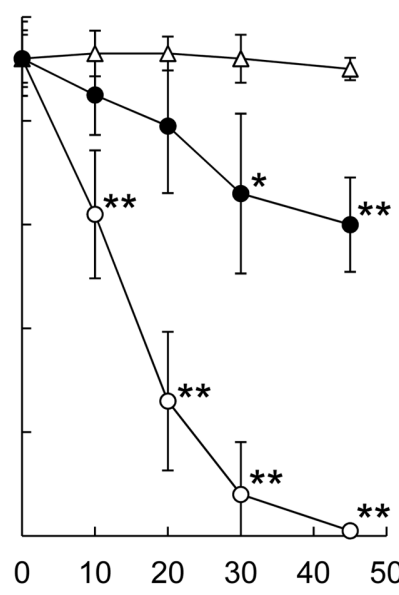

C

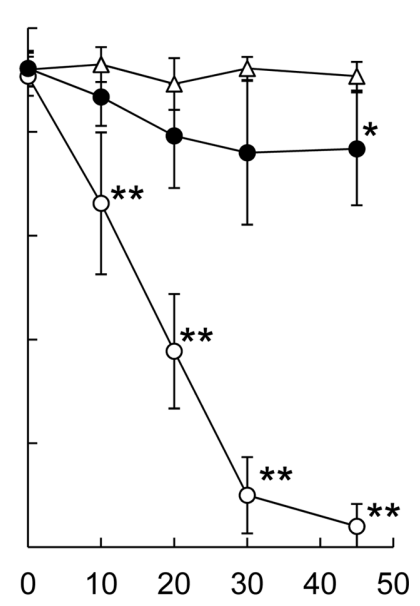

Time $(\min )$

Fig. 3 Time-dependent effect of LPS on HL60 cells (A), THP-1 (B) cells and HGFs (C). $500 \mu \mathrm{g} \mathrm{ml} \mathrm{l}^{-1}$ LPS incubation for various times; $\bigcirc$, Aa-LPS; Ec-LPS; $\triangle$, PBS. The results are expressed as the mean \pm standard deviation of four independent experiments. Single asterisk indicates significant difference from PBS $(P<0.05)$; double asterisk indicates significant difference from PBS $(P<0.01)$.

reading of the paper and helpful comments. This study was supported in part by a Grant-in-Aid for SPSR from MECSST 2008-12.

\section{References}

1. Meyer DH, Fives-Taylor PM: The role of Actinobacillus actinomycetemcomitans in the pathogenesis of periodontal disease. Trends In Microbiol, 5: 224-228, 1997.

2. Wilson M, Henderson B: Virulence factors of Actinobacillus actinomycetemcomitans relevant to the pathogenesis of inflammatory periodontal diseases. FEMS Microbiol Rev, 17: 365-379, 1995.

3. Akifusa S, Poole S, Lewthwaite J, Henderson B, Nair SP: Recombinant Actinobacillus actinomycetemcomitans cytole- 
thal distending toxin proteins are required to interact to inhibit human cell cycle progression and to stimulate human leukocyte cytokine synthesis. Infect Immun, 69: 5925-5930, 2001.

4. Belibasakis G, Johansson A, Wang Y, Claesson R, Chen C, Asikainen S, Kalfas S: Inhibited proliferation of human periodontal ligament cells and gingival fibroblasts by Actinobacillus actinomycetemcomitans: involvement of the cytolethal distending toxin. Eur J Oral Sci, 110: 336-373, 2002.

5. Fives-Taylor PM, Meyer DH, Mintz KP, Brissette C: Virulence factors of Actinobacillus actinomycetemcomitans. Periodontol 2000. 20: 136-167, 1999.

6. Balashova NV, Crosby JA, Al Ghofaily L, Kachlany SC: Leukotoxin confers beta-hemolytic activity to Actinobacillus actinomycetemcomitans. Infect Immun, 74: 2015-2021, 2006.

7. Henderson B, Wilson M, Sharp L, Ward JM: Actinobacillus actinomycetemcomitans. J Med Microbiol, 51: 1013-1020, 2002.

8. Kamin S, Harvey W, Wilson M, Scutt A: Inhibition of fibroblast proliferation and collagen synthesis by capsular material from Actinobacillus actinomycetemcomitans. J Med Microbiol, 22: 245-249, 1986.

9. White PA, Wilson M, Nair SP, Kirby AC, Reddi K, Henderson B: Characterization of an antiproliferative surface-associated protein from Actinobacillus actinomycetemcomitans which can be neutralized by sera from a proportion of patients with localized juvenile periodontitis. Infect Immun, 63: 2612-2618, 1995.

10. Brandenburg K, Wiese A: Endotoxins: relationships between structure, function, and activity. Curr Top Med Chem, 4: 1127 -1146, 2004.

11. Newnham JP, Shub A, Jobe AH, Bird PS, Ikegami M, Nitsos I, Moss TJM. The effects of intra-amniotic injection of periodon- topathic lipopolysaccharides in sheep. Am J Obstet Gynecol, 193: 313-321, 2005

12. Li Y, Shibata Y, Zhang L, Kuboyama N, Abiko Y: Periodontal pathogen Aggregatibacter actinomycetemcomitans LPS induces mitochondria-dependent-apoptosis in human placental trophoblasts. Placenta, 32: 11-9, 2011.

13. Chen LL, Yan J: Porphyromonas gingivalis lipopolysaccharide activated bone resorption of osteoclasts by inducing IL-1, TNF, and PGE. Acta Pharmacol Sin, 22: 614-618, 2001.

14. Morrison DC, Kline LF: Activation of the Classical and Properdin Pathways of Complement by Bacterial Lipopolysaccharides (LPS). J Immunol, 118: 362-368, 1977.

15. Williamson SI, Wannemuehler MJ, Jirillo E, Pritchard DG, Michalek SM, McGhee JR: LPS regulation of the immune response: separate mechanisms for murine B cell activation by lipid A (direct) and polysaccharide (macrophagedependent) derived from Bacteroides LPS. J Immunol, 133: 2294-2300, 1984.

16. Moran AP, Helander IM, and Kosunen TU. Compositional analysis of Helicobacter pylori rough-form lipopolysaccharides. J Bacteriol 174: 1370-1377, 1992.

17. Takada K, Hirasawa M: Isolation and characterization of nonpigmented rough colony of Porphyromonas gingivalis from periodontitis. Anaerobe, 4: 233-240, 1998.

18. Dubois M, Gilles KA, Hamilton JK, Rebers PA, Smith F: Colorimetric method for determination of sugars and related substances. Anal Chem, 28: 350-356, 1956.

19. Brogan JM, Lally ET, Poulsen K, Kilian M, Demuth DR: Regulation of Actinobacillus actinomycetemcomitans leukotoxin expression: analysis of the promoter regions of leukotoxic and minimally leukotoxic strains. Infect Immun, 62: 501-508, 1994. 